\title{
Electronic Clinical Challenges and Images in GI
}

\section{Rare Complication: What Kind of Colitis?}

Q1 Ana Célia Caetano, ${ }^{1,2}$ Bruno Gonçalves, ${ }^{1}$ and Carla Rolanda ${ }^{1,2}$

${ }^{1}$ Department of Gastroenterology, Braga Hospital, and ${ }^{2}$ Life and Health Sciences Research Institute (ICVS), School of Health Sciences, University of Minho, Braga, Portugal
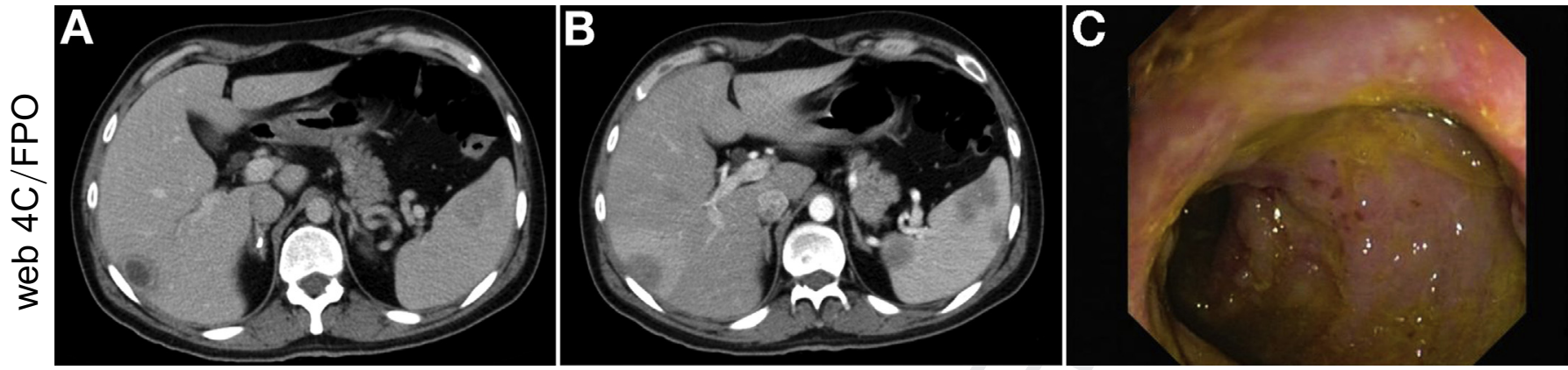

Question: A 39-year-old Caucasian man, who had been working in Angola for 3 years, presented to a private hospital with a 5-week history of bloody diarrhea, anorexia, and weight loss. Colonoscopy showed several spreading ulcers in the right colon with nonspecific inflammation on histology. Abdominal computed tomography (CT) showed thickening of the right colon with no other change. The presumptive diagnosis of colonic Crohn's disease was made and oral corticosteroid therapy was started $(0.75 \mathrm{mg} / \mathrm{kg}$ per day oral prednisone for 12 days).

He then presented to our emergency department with a 3-day history of right-sided abdominal pain and fever. Physical examination revealed a slight tenderness of the right abdomen. Hematologic and biochemical tests showed mild anemia (13 $\mathrm{g} / \mathrm{dL})$, leukocytosis $(13900 \mathrm{U} / \mu \mathrm{L})$, and a raised concentration of C-reactive protein $(141 \mathrm{mg} / \mathrm{L})$. CT (Figure $A, B)$ and colonoscopy (Figure C) were performed.

What is the most likely diagnosis?

See the Gastroenterology web site (www.gastrojournal.org) for more information on submitting your favorite image to Clinical Challenges and Images in GI.

Conflicts of interest: The authors disclose no conflicts.

(C) 2013 by the AGA Institute 0016-5085/\$36.00

http://dx.doi.org/10.1053/j.gastro.2013.06.048 


\section{Electronic Clinical Challenges and Images in GI, continued}

111

112

113

114

115

116

117

118

119

120

121

122

123

124

125

126

127

128

129

130

131

132

133

134

135

136

137

138

139

140

141

142

143

144

145

146

147

\section{Answer to the Clinical Challenges and Images} in GI Question: Image 4: Amoebiasis

Abdominal CT showed 2 liver abscesses $(<20 \mathrm{~mm})$ and multiple splenic nodular lesions $(<35 \mathrm{~mm}$; Figure $A, B)$. Colonoscopy revealed several superficial ulcers and the mucosa of the right colon and cecum was diffusely inflamed and edematous (Figure C). Stool analysis including parasitologic examination was negative. The patient tested positive for serum antiamoebic antibody at a titer of $1 / 320$. The diagnosis of intestinal and extraintestinal amoebiasis was established. He started metronidazole $750 \mathrm{mg} / \mathrm{d}$ for 2 weeks with clinical improvement. Abdominal CT was repeated 3 weeks later and showed no hepatosplenic lesions. A second colonoscopy was performed, showing multiple scars in the right colon causing an asymptomatic stenosis of the hepatic flexure (Figure $D$ ).

Amoebiasis is caused by the protozoan Entamoeba histolytica.

Infection with E bistolytica can lead to amoebic colitis and extraintestinal complications. ${ }^{1}$ In developed countries, most cases occur in immigrants or travelers from endemic areas. The standard of treatment is metronidazole followed by a second agent to eradicate colonization. Gross findings in colonoscopy can strongly resemble those seen in inflammatory bowel disease. Disease severity is increased in individuals with amoebic colitis who mistakenly received corticosteroid therapy. ${ }^{1,2}$

\section{References}

1. Stanley SL Jr. Amoebiasis. Lancet 2003;361:1025-1034.

2. Kanani SR, Knight R. Relapsing amoebic colitis of 12 years' standing exacerbated by corticosteroids. Br Med J 1969;2:613-614.

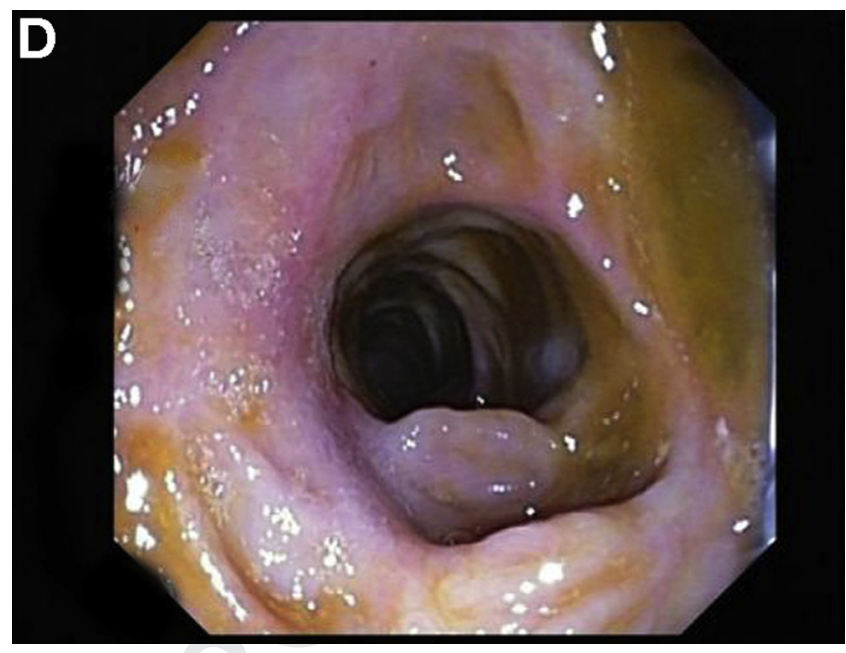

148

149

150

151

152

153

154

155

○ 156

157

158

$\checkmark 159$

을 160

\ 161

162

163

164

165

166

167

168

169

170

171

172

173

174

175

176

177

178

179

180

181

182

183

184 